\title{
Une urgence... depuis les années 1980
}

\section{Groupe d'information sur les Amérindiens}

Aurore Monod Becquelin (éd.)

Traducteur : Aurore Monod Becquelin

\section{(2) OpenEdition}

1 Journals

Édition électronique

URL : https://journals.openedition.org/jsa/10622

DOI : 10.4000/jsa. 10622

ISSN : 1957-7842

Éditeur

Société des américanistes

Édition imprimée

Date de publication : 20 décembre 2008

Pagination : 179-203

ISSN : 0037-9174

Référence électronique

Groupe d'information sur les Amérindiens, " Une urgence... depuis les années 1980 », Journal de la Société des américanistes [En ligne], 94-2 | 2008, mis en ligne le 21 avril 2009, consulté le 03 septembre 2022. URL : http://journals.openedition.org/jsa/10622 ; DOI : https://doi.org/10.4000/jsa.10622

Tous droits réservés 


\title{
CHRONIQUE DU GROUPE D'INFORMATION SUR LES AMÉRINDIENS
}

\author{
BRÉSIL
}

\section{UNE URGENCE... DEPUIS LES ANNÉES 1980}

Note Liminaire : le 10 décembre 2008, selon une information diffusée le 11 par Survival (voir http://www.survivalfrance.org/actu/4027), le Tribunal Suprême Fédéral du Brésil, par huit voix sur onze, semble avoir clos l'affaire qui est présentée dans les pages suivantes, en rejetant l'appel des occupants illégaux du territoire indigène de Raposa Serra do Sol.

\section{INTRODUCTION}

Une fois encore, la démarcation d'un territoire indigène se trouve menacée après des années de procédures et une conclusion légale en faveur des Indiens. Mais, cette fois-ci, l'enjeu dépasse la délimitation des terres, la survie des groupes, le respect des langues et des cultures jusque dans leurs transformations. C'est que le recul du gouvernement, par une décision du Tribunal Suprême Fédéral qui contreviendrait à la loi, mettrait en péril d'annulation toutes les décisions qui ont été prises dans les mêmes conditions. Si la loi est bafouée ici et maintenant - donner raison aux contrevenants après une décision de justice les condamnant -, alors elle le sera rétroactivement dans tous les cas identiques. Si une poignée de riziculteurs illégalement installés dans un territoire indigène gagne devant la nation contre des occupants légaux dont le statut est inscrit dans la Constitution et après jugement du tribunal compétent, alors il ne sera plus question de parler de langues en danger ou de cultures en danger, c'est la survie ethnique qui est en jeu, sans parler de la survie des êtres humains projetés dans un futur sans avenir.

Pour informer les américanistes sur ce dossier, on propose ici quatre types d'informations ${ }^{1}$ :

- la lettre de l'Association Brésilienne d'Anthropologie, envoyée au Président Lula, qui fait appel de la situation, ainsi que la lettre du professeur Luis 
Cardoso, président de cette même association (documents 1 en français; traduction d'Aurore Monod Becquelin).

- un extrait de l'interview, par un journaliste, d'Eduardo Viveiros de Castro, professeur d'anthropologie au musée national de l'université fédérale de Rio de Janeiro, répondant aux questions les plus fréquemment posées par le public (document 2 en portugais du Brésil).

- un résumé très succinct d'un ensemble de documents rassemblés par l'Institut Socioambiental, dont l'intégralité peut être consultée sur un site internet (référence fournie dans le document 3 en français; traduction d'Aurore Monod Becquelin)

- une lettre d'appui signée par plus de cent cinquante associations, ainsi que des dizaines de particuliers, appelant au respect de la loi et demandant l'expulsion d'occupants illégitimes et violents (document 4 en portugais du Brésil).

\section{TERRE INDIGÈNE RAPOSA SERRA DO SOL. POLÉMIQUE SUR LA DÉMARCATION, LA SOUVERAINETÉ ET LE DÉVELOPPEMENT À LA FRONTIÈRE DU RORAIMA}

\section{Documents 1A-Lettre de l'Association Brésilienne d'Anthropologie sur l'action du gouvernement fédéral relative au territoire indigène Raposa Serra do Sol}

L'association Brésilienne d'Anthropologie se joint à l'ensemble des associations civiles et politiques brésiliennes pour défendre l'homologation de la démarcation du territoire indigène Raposa Serra do Sol comme une aire continue, en en retirant les occupants non indiens (six riziculteurs) conformément au décret pris pendant le premier gouvernement du président Luis Inácio Lula da Silva, en accord avec la défense de la légalité et des principes d'un État de droit, tels qu'ils sont inscrits dans la Constitution de 1988.

Tout au long des cinquante années de son existence, notre association, la première association scientifique dans le domaine des sciences humaines au Brésil et l'une des trois plus grandes associations anthropologiques du monde, s'est engagée pour de nombreuses causes sociales, conformément à l'impératif de responsabilité morale et éthique qui oblige tout anthropologue à défendre les 
groupes sociologiquement minoritaires avec lesquels il travaille ; les occasions de le démontrer ne nous ont pas manqué, que ce soit en période de régime dictatorial ou en démocratie. Notre compétence professionnelle, notre engagement moral et éthique nous ont placés en situation d'agir, fondant les principes de l'action de l'État sur la reconnaissance des droits indigènes aux territoires qu'ils occupent traditionnellement, qu'il s'agisse de documents dont la source est le travail d'identification de ces terres, ou bien sous la forme de laudis periciais à des fins juridiques.

Sur la base de connaissances accumulées depuis plus de vingt ans en intervenant dans des processus d'identification territoriale, et forts d'un consensus dans notre communauté sur les formes scientifiquement adéquates pour le faire, nous croyons que les situations de violence risquent de se multiplier exponentiellement : cette opinion est fondée sur les études anthropologiques menées qui nous informent sur la démarcation déjà réalisée de l'aire Raposa Serra do Sol, occupée par les Indiens Macuxi, Wapixana, Ingarikó, Taurepang et Patamona, victimes de toutes sortes d'agressions.

Nous contestons les atermoiements dans l'expulsion des occupants non indiens et contestons aussi les faveurs politicardes qui favorisent six personnes dont les intérêts politiques délimitent «l'État» de Roraima, en vérité un État indigène dont la richesse véritable repose sur les dix-huit mille habitants des villages indiens, citoyens brésiliens au même titre que nous.

Nous appuyant sur notre expérience partagée, nous voulons souligner fortement que les peuples indigènes ont été les défenseurs des frontières du Brésil pendant la période coloniale, impériale et républicaine, bien avant l'arrivée des habitants non indigènes de Roraima et d'une bonne partie des Amazoniens. Ce qui se passe, soutenu par un pseudo-nationalisme émanant de voix militaires et civiles qui manifestent leur ignorance de la vérité du pays dans lequel nous vivons, est symptomatique des immenses inégalités qui, malheureusement, marquent le Brésil.

L'Association Brésilienne d'Anthropologie se manifeste une fois encore au nom de la démocratie, de la pluralité et de la vérité scientifique, fondements d'une société plus juste, pour inviter fermement le gouvernement fédéral à agir dans l'intérêt de l'ordre, de la loi et de la paix, et à intervenir pour en finir avec de tels abus. Nous le faisons avec une longue expérience de la démarcation des terres indigènes dans les régions frontalières qui, aujourd'hui, se trouvent plus sûres grâce à la présence de ceux qui sont les premiers occcupants légitimes de notre terre.

L'Association Brésilienne d'Anthropologie se tient à la disposition de qui le souhaite pour en débattre et contribuer à une pleine et entière reconnaissance des droits indigènes. 


\section{Documents 1B - Lettre de Luís Cardoso de Oliveira, président de l'ABA}

\section{Terres indigènes et (in) accomplissement de la loi}

En avril 2008, une avalanche de déclarations anti-indigènes s'est abattue sur le pays. Au moment même où se célébrait « la journée de l'Indien » en hommage aux premiers habitants de cette nation, d'ailleurs proche de la fête anniversaire du Brésil, des propos extrêmistes et furieux se déchaînèrent, dénonçant « le chaos de la politique indigéniste », "les privilèges exhorbitants des Indiens » et «les menaces qu'ils représentent pour la sécurité nationale ». De hautes autorités s'exprimèrent avec une naïveté et un laisser-aller qui seraient à peine admissibles dans la vie privée et dans l'anonymat.

Une véritable vague de désinformation se répand via les médias, créant dans l'opinion publique l'illusion que tout se réduit à un conflit d'opinions. Le débat se réduit à une seule aire parmi les cinq cents et plus qui ont été démarquées par la FUNAI. Comme dans les "reality shows», exercice schizophrénique d'une parodie de démocratie dans un empire de consommation de masse, l'étape suivante est de créer le mirage d'une sorte de plébiscite sur un sujet nouveau pour l'État, comme s'il n'existait pas de mécanismes juridiques et administratifs adaptés : qui a raison, les Indiens ou les riziculteurs ? les organisations non gouvernementales ou le commandement militaire de l'Amazonie?

Une telle approche est injustifiable et totalement biaisée. La législation indigéniste brésilienne est extrêmement détaillée et fixe précisément les critères et les processus à suivre dans chaque cas. Au milieu des années 1990, sous le ministère de la Justice de Nelson Jobim, un décret est paru, reconnaissant la place des contradicteurs dans le processus administratif de démarcation. Ce qui veut dire qu'aucune terre indigène ne peut être reconnue officiellement sans que soient annexés au dossier, entendus et examinés les arguments de tous ceux qui pourraient se sentir lésés par l'action exécutoire.

Toute proposition de création d'un territoire indigène est publiée par la FUNAI au Journal Officiel de l'Union, ouvrant ainsi un délai pour que tous aient le loisir de se manifester. Les propriétaires de terrains, les faussaires (grileiros ${ }^{2}$ ), toutes les sortes d'associations, les syndicats de travailleurs ou de patrons, les préfectures, les organes publiques fédéraux et de l'État font un usage extensif du droit de s'opposer. Sont joints au dossier, par les procureurs, avocats, politiques et personnalités, toutes les preuves et tous les documents considérés comme pertinents. La décision finale est prise, non par quelqu'un qui serait susceptible de subir des pressions de la part des Indiens - comme par exemple ce pourrait être le cas pour le président de la FUNAI -, mais par un ministre d'État, le ministre de la Justice.

La démarcation géographique d'un territoire demande de nombreuses années en raison des restrictions budgétaires et des priorités de chaque gestion. Pendant cette phase, les bénéficiaires d'une installation qui sont de bonne foi sont indem- 
nisés, et l'INCRA réinstalle les possesseurs de terrain et petits propriétaires qui étaient installés auparavant. C'est seulement ensuite que l'aire peut être homologuée par le président de la République, après un passage au crible de la « Casa Civil » et du Cabinet militaire (autrefois par le Conseil national de Sécurité). À un certain moment, l'État doit aboutir à une décision finale, accordant aux victimes les droits qui leur ont été déniés. C'est dire que, dans ce long périple, il n'y a d'espace ni pour la précipitation, ni pour des actions arbitraires. Au contraire, ce que l'on peut observer, c'est que la lenteur excessive dans l'accomplissement de la loi génère des préjudices irréversibles, causes d'obstacles à la reconnaissance des droits qui sont dûs aux Indiens, consumant l'énergie de générations entières et compromettant gravement l'écologie du milieu qui leur est destiné.

C'est exactement le cas du territoire indigène Raposa Serra do Sol. En dépit du fait que toutes les exigences, phases et délais du processus aient été minutieusement respectés, les intérêts des riziculteurs et du gouvernement de l'État de Roraima entendus et examinés - aussi bien au cours du cheminement administratif que des multiples actions judicaires - la voie suivie par les plaignants insatisfaits a été de torpiller l'action aboutie, tentant de tromper l'opinion publique et d'intimider le gouvernement. Les déclarations fulminantes et les actes de violence, comme ceux qui ont été commis ces dernières semaines (mai 2008) contre des manifestants indigènes sans arme, font partie d'une escalade dans les pressions dont le seul but est de provoquer le conflit et de conduire les autorités à douter de la possibilité d'exécuter la procédure. Et pourtant, malgré cette opposition, le gouvernement a clairement exprimé l'intention de poursuivre son action conformément à la loi.

Les anthropologues brésiliens, chaque fois qu'ils ont été sollicités par des instances administatives ou judiciaires, ont contribué de façon décisive au respect des principes légaux et à la reconnaissance des droits des Indiens. Les propositions de démarcation procèdent toujours d'études anthropologiques détaillées réalisées par des chercheurs de formation techno-scientifique de haut niveau (doctorants et docteurs). Les anthropologues suivent les orientations théoriques et méthodologiques de leur discipline, mais également tiennent compte des critères et procédures officiels, tels les arrêtés et les décrets d'application du ministère de la Justice et de la FUNAI.

C'est sur la base de leur expérience que les anthropologues ont contribué de façon positive à la construction d'un Etat démocratique et de droit et qu'ils attendent que les autorités constituées maintiennent avec fermeté l'application de la législation indigéniste, comme l'ont fait clairement le ministre de la Justice et le président de la République lui-même (en accord avec les Indiens). Il ne s'agit pas seulement d'arbitrages relatifs à des sujets restreints ou nouveaux, mais d'activation des postulats qui proviennent d'une longue et solide tradition de la pensée et du droit brésiliens. Seule l'application de la loi pourra garantir les conditions d'une convivialité future entre Blancs et Indiens dans l'État de Roraima. Il est 
essentiel que la politique indigéniste ne demeure pas paralysée par cette polémique caduque et perverse. Il faut que l'action indigéniste gérée à partir d'une structure collégiale et participative, comme le Conseil National de Politique Indigéniste, puisse continuer son immense liste de travaux dont, en priorité, la régularisation de toutes les terres indigènes, ainsi que la recomposition des programmes de santé à l'intention des Indiens. Il y a de nombreux cas de territoires indigènes avec des caractéristiques différentes de celles de Raposa Serra do Sol dont la démarcation, si elle est différée sine die aura pour conséquence de les transformer en nœuds de futurs conflits d'égale gravité.

Brasília, 8 mai 2008

DOCUMENT 2 - Extraits d'une interview du professeur Eduardo Viveiros de Castro publiée par le quotidien Estado de São Paulo, le 20 avril 2008, à propos des conflits touchant la Réserve Raposa Serra do Sol, État de Roraima (Brésil)

$[\ldots]$

$J$ (Journaliste): Existe risco para a soberania nacional na reserva Raposa Serra do Sol, como crê o general?

V (Viveiros de Castro): Existe, sim, uma questão de soberania do governo ao ser contestado publicamente por um membro das Forças Armadas. O general polemiza com uma decisão que, como todo mundo diz, não se discute, apenas se executa. A argumentação de que a reserva indígena represente um problema de soberania está mal colocada.

J: Por quê?

V: Há outras reservas em terras contínuas, em fronteiras. É o caso da Cabeça de Cachorro, no município de São Gabriel da Cachœira, no Estado do Amazonas. E o Exército está lá, como deveria estar. A área indígena não teria como impedir a presença dos militares. O que a área indígena não permite é a exploração das terras por produtores não-índios. Dizer que o Exército não pode atuar é um sofisma alimentado por políticos e fazendeiros que agem de comum acordo, numa coalizão de interesses típica da região. Roraima é um Estado que não se mantém sozinho, ou melhor; que depende do repasse de recursos federais. Um lugar onde $90 \%$ dos políticos nem sequer são nativos. Onde o maior arrozeiro, que está à frente do movimento contra a reserva, arvora-se em defensor da região, mas veio de fora. É um gaúcho que desembarcou por lá em 1978, e não há nada de mal nisso, mas combate os índios que justamente servem de « muralha dos sertões ", desde os tempos da colônia. Os índios foram decisivos para que o Brasil ganhasse essa área, numa disputa que houve no passado com a Guiana, portanto, com a Inglaterra. Dizer que viraram ameaça significa, no mínimo, cometer uma injustiça histórica. Até o mito do Macunaíma, que foi recolhido por um alemão, Koch-Grünberg, e transformado por um paulista, Mário de 
Andrade, foi contado por índios daquela área, os macuxis, os wapixanas. Eles são co-autores da ideologia nacional.

[...]

J: Esse conflito na Raposa tem por volta de 30 anos. Em 2005, quando o presidente Lula homologou as terras, selou-se o compromisso de retirar; no prazo de um ano, os produtores rurais que estavam dentro da área reservada. Parecia que todo mundo ficara de acordo. Por que a situação se deteriorou?

V: Há o jogo político. Disseminam-se inverdades, como a de que a área da reserva ocupa $46 \%$ de Roraima, quando apenas ocupa $7 \%$. As terras indígenas de Roraima, somadas, dão algo como $43 \%$ do Estado. Mas a Raposa tem $7 \%$.

$J: O u, 1,7$ milhão de hectares.

V: O que nãoé um absurdo. As terras de índios são $43 \%$ ao todo, porém, até 30 , 40 anos atrás, eram $100 \%$. E o que acontece hoje com os $57 \%$ que não são terras de índios? São ocupados por uma população muito pequena, algo em torno de 1 milhão de pessoas. O que é isso? É latifúndio. Sabe quantos são os arrozeiros que exploram terras da reserva? Seis. Não há dúvida de que o que se quer são poucos brancos, com muita terra. Outra inverdade: as terras da reserva são dos índios. Não são. Eles não têm a propriedade, mas o usufruto. Porque as terras são da União. E a União tem o dever constitucional de zelar por elas. Já os arrozeiros querem a propriedade. As notícias que temos são as de que, desde a homologação, produtores rurais que estão fora da lei já atacaram quatro comunidades indígenas, incendiaram 34 casas, arrebentaram postos de saúde, espancaram e balearam índios. Paulo César Quartiero, o arrozeiro-mor, foi preso na semana passada por desacato à autoridade. Já está solto, mas, enfim, esse é o clima de hostilidade que reina por lá. Sinceramente, acho que o general Heleno está sendo usado por esses tubarões do agronegócio, que o envolvem numa questão de soberania totalmente artificial. O general cai nessa e vem com uma tese de balcanização, que não faz o menor sentido. Ele disse à imprensa: « $O$ risco de áreas virem a se separar do território brasileiro, a pedido de índios e organizações estrangeiras, pode ser a mesma situação que ocorreu em Kosovo ». Muito bem, o general raciocina como se nós fôssemos os sérvios? Por acaso seria o Brasil a Sérvia e os índios, minorias que precisam ser eliminadas? Não estou entendendo.

$J$ : $O$ que se questiona na Raposa é a criação de uma reserva enorme, em área contínua.

V: A declaração do ministro Gilmar Mendes a esse respeito é espantosa. Ele defende a demarcação de ilhas, e não de terras extensas. Em primeiro lugar, não sabia que ministro do Supremo é demarcador de terras. Demarcar é ato administrativo, cabe ao governo, não ao Judiciário. Em segundo lugar, as terras indígenas já são um arquipélago no Brasil. Acho curiosa essa expressão: demarcar em ilhas. Significa ilhar, isolar, separar. Demarcar de modo que um mesmo povo fique separado de si mesmo. 
J: Existe o risco de reivindicação de autonomia por parte dos índios?

V: A terra ianomâmi está demarcada desde o governo Collor e nunca houve isso. Alguém imagina que os ianomâmis queiram reivindicar um Estado independente, justamente um povo que vive numa sociedade sem Estado? Chega a ser engraçado.

$J:$ E se eles foram manipulados por interesses estrangeiros?

V: Empresas e cidadãos estrangeiros já são proprietários de partes consideráveis do Brasil. Detêm extensões enormes de terra e parece não haver inquietação em relação a isso. Agora, quando os índios estão em terras da União, que lhes são dadas em usufruto, daí fala-se do risco de interesses estrangeiros. A Amazônia já está internacionalizada há muito tempo, não pelos índios, mas por grandes produtores de soja ligados a grupos estrangeiros ou pelas madeireiras da Malásia. O que não falta por lá é capital estrangeiro. Por que então os índios incomodam? Porque suas terras, homologadas e reservadas, saem do mercado fundiário.

J: É uma questão fundiária?

V: É. Essa história de soberania nacional serve para produzir pânico em gente que vive longe de lá. É claro que o Exército tem de cumprir sua missão constitucional, que não é a de ficar criticando o Executivo, é proteger fronteiras, fincar postos de vigilância, levar seus batalhões, criar protocolos de convivência com as populações locais. Mas o que prevalece é o conflito fundiário e a cobiça pelas terras. Veja o que aconteceu no Estado do Mato Grosso. O que fez esse governador (Blairo Maggi), considerado um dos maiores desmatadores do mundo? Derrubou florestas para plantar soja, com o consentimento do presidente da República, diga-se de passagem. Hoje o Estado do Mato Grosso deveria se chamar Mato Fino. Virou um mar amarelo. $O$ único ponto verde que se vê ao sobrevoá-lo é o Parque Nacional do Xingu, reserva indígena. O resto é deserto vegetal. Uma vez por ano, o deserto verdeja, hora de colher soja. Depois, dá-lhe desfolhante, agrotóxico... E a soja devasta a natureza duplamente. Cada quilo produzido consome 15 litros de água. Em Roraima não se deve bater de frente com o Planalto. Representa esse Estado o senador Romero Jucá, que é pernambucano e hoje atua como líder do governo. Jucá tem interesses claros e bem definidos. É dele o projeto que regulamenta a mineração em terras indígenas. Regulamenta, não. Libera.

J: Ele foi presidente da Funai.

V: Num momento particularmente infeliz da política indigenista brasileira. Olha, não há nada de errado em ser gaúcho ou pernambucano e fazer a vida em Roraima. Mas não precisa isolar as comunidades e solapar seus direitos. Outra aspecto precisa ser lembrado: até que saísse a homologação da Raposa, o que demorou anos e anos, muito foi tirado de lá. A sede do município de Uiramutã, com $90 \%$ de índios entre seus moradores, foi transferida para fora da área. Estradas federais cortam a reserva, bem como linhas de transmissão elétrica. A rigor, já não é uma terra tão contínua. 
J: O general diz que a política indigenista no Brasil é lamentável e caótica. Concorda com ele?

V: melhor hoje. Em alguns aspectos tem problemas, sim, como nos programas de saúde para populações indígenas, desastrosos desde que passaram para a coordenação da Fundação Nacional de Saúde (Funasa). Tem havido desmandos e irregularidades em toda parte. Mas do ponto de vista de relacionamento dos indígenas com os poderes da República, as coisas não estão tão mal assim.

$[\ldots]$

Reina uma abissal ignorância sobre a realidade desses povos de quem somos devedores.

\section{J: Por quê?}

$\mathrm{V}$ : O brasileiro vive um complexo que eu chamaria de a nostalgia de não ser europeu puro. Isso também se traduz no medo de ser confundido com índio. É um complexo de inferioridade. Ser « um pouco índio » até cai bem na medida em que existe uma certa simpatia com a idéia de mistura de raças, o que também não deixa de ser ambíguo. Por outro lado, o estereótipo clássico do índio, aquele sujeito de cocar e tanga, cada vez menos espelha a realidade. $\mathrm{O}$ caboclo da Amazônia pode ter hábitos tipicamente indígenas, mas é também o sujeito que vê televisão, fala ao telefone, como nós.

\section{[...]}

J: A desconfiança em relação a possíveis pleitos de autonomia tem a ver com o que se passa na Bolívia, país que mudou a constituição para atender aos indios?

V: É interessante como se tem invocado a Bolívia ultimamente. A população daquele país é quase toda indígena, enquanto no Brasil falamos de uma minoria irrisória. Zero vírgula zero alguma coisa. Lá é briga de índio. Curioso o Brasil temer virar uma Bolívia, quando uma das tensões sociais que se vê hoje por lá é justamente a presença de brasileiros. São grandes proprietários de terra.

J: As reivindicações dos índios na Bolivia podem ser imitadas aqui?

V: Mas o que os nossos índios estão pedindo? Passaporte de outro país? Dupla nacionalidade? Uma bandeira só para eles? Uma outra Constituição? Nada disso. O que eles pedem é justamente maior presença do Estado brasileiro onde vivem, para não depender da intermediação do político local. Isso os constitui como uma nação à parte, no sentido jurídico? Evito esse conceito, porque tudo é nação no Brasil.

J: Como assim?

V: Tem nação nagô, nação rubro-negra, nação corintiana. Essa também é uma herança de Portugal, que, no passado, tratava os povos como nações em documentos administrativos. A rigor, nação é uma construção subjetiva, um compartilhamento de sentimentos e cultura. É isso. Mas a turma do discurso do pânico pensa assim: primeiro o índio tinha vergonha de ser índio, depois viu que 
é bom ser comunidade. Daí ganhou terra, vai querer autonomia e fundar uma nação. Ora, quem diz isso nunca colocou o pé numa terra indígena.

$$
\text { [...] }
$$

J: Professor, quem é, afinal, indio no Brasil?

V: Vamos mudar a pergunta: quem está autorizado a dizer que é índio? Eu não estou. Esse é um problema fundamental: quem está autorizado a dizer quem é quem, quem é o quê. Fazer disso uma questão de peritagem me parece uma coisa monstruosa. Ninguém se inventa índio, ninguém sai por aí reivindicando uma identidade escondida, recalcada, eu diria. Vá ver de perto e descobrirá que é assim que a coisa acontece. Portanto, não é índio quem quer. Mas quem pode. Não é negro quem quer. Mas quem pode.

\section{[...]}

J: Diz-se que 49,5\% dos 225 povos indigenas do Brasil são constituídos, cada um, de no máximo 500 indivíduos. Vem dai a idéia de que é pouca gente para muita terra?

V: Mas no Estado de Roraima há meia dúzia de arrozeiros fazendo esse estardalhaço todo. Meia dúzia! Também não é pouca gente? Como é que comunidades tão pequenas podem ameaçar o Brasil? Só se forem criar Estados de Mônaco. Utilizar o índio como modelo de latifúndio, como se tem feito, é um prodígio de má-fé. Índio também vende madeira? Claro que vende. Mas só ele? E os outros?

J: Desses 225 povos, 36 têm populações parte no Brasil, parte em países vizinhos. Não é um potencial de conflito imenso?

V: Se algum país está o preocupado com isso, certamente não é o Brasil. O fato de haver guaranis no Brasil e na Argentina é mais problema para o vizinho. Compare as duas populações, compare o tamanho dos países. Ter ianomâmis no Brasil e na Venezuela sempre foi complicado para o lado de lá, porque a Venezuela tem petróleo. Mas agora o Brasil também tem, nem precisamos ficar mais com complexo de inferioridade (risos). Qualquer tentativa de ver um problema aí é artificial. O que se sugere? Que se levante uma cortina de ferro para impedir que os ianomâmis passem de um lado para o outro? Por que índios podem cruzar a fronteira Brasil-Uruguai livremente, e não podem cruzar a fronteira Brasil-Venezuela? Por que temos medo do Chávez? Ter comunidades dos dois lados faz da fronteira uma zona de frouxidão. Será que é isso? A fronteira mais complicada do Brasil, hoje, é com a Colômbia, por causa das Farc, e os índios não têm nada a ver com isso. Aliás, eles atrapalham a guerrilha.

\section{J: Por quê?}

V: Porque há mais presença do Estado nas áreas onde vivem. Não vejo como os índios possam perturbar a segurança de nossas fronteiras e, lembrem-se, populações binacionais existem em várias partes do mundo. Pensemos também no bilingüismo. Até final século $18 \mathrm{em}$ São Paulo falava-se a língua geral, o nhangatu, uma derivação do tupi. Foi uma língua imposta pelos missionários, 
até hoje ouvida em alguns locais da Amazônia. Mas ainda ouvimos cerca de 150 línguas indígenas, o que representa uma diversidade incrível. Algumas dessas línguas são tão diferentes entre si quanto o português do russo, até porque pertencem a troncos diferentes. E são faladas por indivíduos bilíngües, que adotam também o português no dia-a-dia.

J: Digamos que os não-índios deixem a Raposa. Os índios de lá poderão plantar e fazer lucro? Poderiam virar arrozeiros?

V: Sim, podem plantar e vender. Podem até virar arrozeiros. Mas terão de produzir dentro de limites muito estritos, sujeitos a leis ambientais severas, não se esqueça de que a reserva integra o Parque Nacional de Roraima. Também não podem explorar o subsolo, a não ser o que há no solo de superfície. Mas francamente acho que a população indígena jamais entrará de cabeça no modo de produção do agronegócio, que eu chamo de modelo gaúcho, porque isso simplesmente não bate com seu modelo de civilização. Por isso insisto tanto em dizer que estas não são terras de índio, mas terras de usufruto dos índios. Nunca houve polêmica sobre a definição de reserva, porque se sabe que o domínio das terras é da União. Isso é inclusive a maior garantia para os índios. No dia em que não houver mais, eles serão invadidos imediatamente. Inclusive pelo Brasil, inclusive pelos arrozeiros. Só que no sentido técnico essa invasão já houve. Os índios não têm soberania porque já a perderam e se renderam. Suas populações foram invadidas, exterminadas, derrotadas. O que eles querem é que os direitos de vencidos sejam respeitados. Não se pode infligir uma segunda derrota a eles. Isso é contra as leis, contra tudo.

$[\ldots]$

Estadao.com.br | O Estado de S.Paulo | Jornal da Tarde | Agência Estado | Radio Eldorado Listas | OESP. Copyright (C) Grupo Estado. Todos os direitos reservados. Reproduit avec l'aimable permission du Journal et des auteurs.

\section{DOCUMENT 3}

Il s'agit ici de souligner quelques points d'un ensemble de documents politiques, administratifs et médiatiques rassemblés par l'Institut Socioambiental (ISA) ${ }^{3}$, qui comprend :

- des articles, au nombre de 45, signés par des chercheurs, des autorités politiques, administratives ou religieuses, des avocats et des journalistes brésiliens ;

- des brèves, soit 102 extraits d'articles des principaux journaux brésiliens, ainsi que des lettres collectives (associations professionnelles et ONG);

- des documents administratifs - y compris des cartes ;

- une chronologie des événements, synthétique d'abord pour la période de 1904 à 2004, puis détaillée de 2004 à mai 2008. 
Le dossier complet peut être consulté sur le site : www.socioambiental.org.

La documentation mise en ligne, chronologiquement ordonnée, fournit, outre des discussions, des articles et des citations, les références précises aux lois et aux décrets d'application qui concernent ce conflit ainsi que le cadre général de la politique indigéniste. Avocats, historiens, anthropologues, politiques, journalistes, administrateurs de la FUNAI, hommes de terrain s'expriment et s'affrontent sur les problèmes d'intégrité territoriale (délimitation en îlots discontinus ou en territoire continu), sur la politique indigéniste (intégration ou multiculturalisme), sur la sécurité des frontières (troublées ou sécurisées par les groupes indigènes), sur la souveraineté nationale (menacée par l'emprise des ONG étrangères), sur l'écologie (productivité dévastatrice ou ethnoculture conservatrice du milieu ambiant), sur les différents calculs concernant les proportionalités territoriale et démographique, et même, dans la bouche d'un ministre, gouverneur et sénateur de surcroît, sur la caractérisation d'Indiens "primitifs » au regard d'Indiens « acculturés ». Nous avons choisi, ordonné et pourvu de titres ou de commentaires quelques extraits illustrant chacun de ces thèmes pour donner au lecteur le désir de mieux comprendre l'extrême gravité des événements en recherchant les documents sources. L'auteur et la référence du document original sont indiqués entre parenthèses, la position de l'extrait dans le document général de l'ISA apparaît entre crochets pour faciliter la consultation internet.

La liste des abbréviations se trouve à la fin du texte.

1 - Le fondement légal du rapport entre les populations indigènes et la nation brésilienne se trouve exprimé dans l'article 231 de la Constitution (O fundamento legal das relações entre os povos indigenas e a nação se encontra expressado no artigo 231 da constitução)

O artigo 231 da Constituição brasileira: «São reconhecidos aos índios sua organização social, costumes, línguas, crenças e tradições, e os direitos originários sobre as terras que tradicionalmente ocupam, competindo à União demarcá-las, proteger e fazer respeitar todos os seus bens ». (Marcelo Leite, FSP, 20/04/2008 [Mais, p. 9], p. 22)

2 - L'aire fut délimitée par le ministère de la Justice, décret 820/98, en décembre 1998, sous la présidence de Fernando Henrique Cardoso ( A área foi demarcada pelo Ministerio da Justícia, decreto 820198, dizembro 1998, F. H. Cardoso sendo presidente da República)

Da área de Roraima, 46,35\% são reservados aos indígenas. Ali eles somam 46.106, distribuídos em 152 aldeias dos povos Yanomami (15 mil), Macuxi, Wapixana, Wai-Wai, Ingaricó, Taurepang, Waimiri-Atroari e Patamona. (Frei Betto, $C B, 09 / 05 / 2008$ [Opinião, p. 25], p. 62)

3 - La conclusion « définitive » des actes s'est faite le 20 avril 2005 après plus de 20 années de luttes ( A conclusão definitiva dos atos foi feita o dia 20 de abril 2005 depois de mais de vinte anos de luta) 
Em 15 de abril de 2005, o presidente Lula assinou um decreto que o fará lembrado pelas próximas gerações de brasileiros. Ao concluir a demarcação da terra indígena Raposa Serra do Sol, pôs um ponto final em 20 anos de conflito e assegurou a realização do direito constitucional de 18 mil índios que habitam um dos lugares mais bonitos do país.

Outros interesses públicos nacionais relevantes também foram preservados. A homologação abriu uma nova etapa no desenvolvimento da região e afirmou a soberania do povo brasileiro sobre porção estratégica de nosso território.

Todos aqueles que participaram da luta pelo cumprimento da Constituição sabem como foi duro o caminho percorrido até que chegássemos a essa decisão simbólica, hoje reconhecida como um dos pontos culminantes da política indigenista.

$[\ldots]$

Há, portanto, uma sobreposição de regimes jurídicos especiais, todos constitucionalmente protegidos - defesa da soberania territorial, direitos dos índios, conservação ambiental, autonomia do ente federativo e respeito a sua legítima aspiração ao desenvolvimento.

Para chegar a uma solução justa e equilibrada, foram feitas várias visitas « in loco » e executados rigorosos estudos técnicos. Todas as partes envolvidas foram consultadas e ouvidas. (Márcio Thomaz Bastos e Luiz Armando Badin, FSP, 20/04/2008, [Tendências/Debates, p. A3], p. 19)

4 - Après la définition du territoire en 1992 par la FUNAI, la publication de la démarcation avait été soumise à examen et contestation publique dès 1996, selon la loi ; aucun recours n'a été enregistré (Depois da demarcação e homologação do territorio en 1992 pela FUNAI, a publicação do levantamento foi sobmetida à contestação pública desde 1996, de acordo com a lei; não houve ninguna contestação)

De acordo com a advogada do Instituto Socioambiental (ISA), Ana Paula S. Maior, ceder a esse tipo de pressão seria um retrocesso. A advogada conta que após a identificação da Raposa Serra do Sol, concluída em 1992, houve três meses para que pessoas interessadas contestassem a delimitação. "Questões relativas à soberania nacional, à integridade territorial de Roraima e à ocupação dos arrozeiros já foram amplamente discutidas no bojo desse processo. São preocupações plenamente superadas ». (F. Dourado, Com Ciência, 08/05/2008, p. 60)

Se o leitor duvida, pergunte-se porque não constam eles, nominalmente, do levantamento fundiário realizado pela FUNAI em 1992, passo necessário para a delimitação da Terra Indígena Raposa-Serra do Sol? E porque não se manifestaram eles em 1996, quando o Executivo, em cumprimento ao Decreto $1775 / 96$, expôs a demarcação da terra indígena à contestação pública? A resposta é simples: não estavam lá, esses que hoje 
afrontam a Constituição e, portanto, o Estado de Direito tão duramente conquistado por todos nós. (Nádia Farage, Agência Estado, 22/04/ 2008, p. 24)

5 - Une chronologie du droit et des événements : la démarcation est légale au regard du droit (Cronología do direito e dos acontecimentos: a demarcação è juridicamente legal)

O Supremo Tribunal Federal, oportunamente chamado a se manifestar, decidiu favoravelmente à edição do decreto homologatório, removendo os obstáculos jurídicos que até então impediam a resolução definitiva do conflito por quem tinha competência legal, instrumentos e meios para fazê-lo: o Poder Executivo. Foram tomados todos os cuidados para dar consistência jurídica e política à decisão do presidente.

A solução adotada harmonizou os vários interesses públicos nacionais e deu máxima eficácia a um feixe de normas da Constituição Federal. Roraima foi beneficiada por medidas compensatórias, em um plano de desenvolvimento social e econômico.

A maioria dos ocupantes não índios que, de boa-fé, ainda permaneciam na área, foi pacificamente reassentada. Assegurou-se plena liberdade de atuação às Forças Armadas e à Polícia Federal.

A presença soberana e incontrastável do Estado brasileiro foi conciliada com a proteção do meio ambiente e da diversidade étnica e cultural, bens valiosos que a Constituição, generosamente, soube reconhecer.

Falta apenas finalizar a execução do decreto presidencial, concluindo o processo de extrusão da minoria remanescente. Ela já teve mais de três anos para deixar a área invadida. Não é momento de retroceder. (Márcio Thomaz Bastos e Luiz Armando Badin, FSP, 20/04/2008 [Tendências/Debates, p. Â, pp. 19-20)

Les procédés d'identification, de démarcation, d'homologation ont été réguliers (Procesos de identificação, demarcação e homologação foram cumpridos dentro da lei)

Pois a verdadeira questão é o (des)respeito ao Estado de Direito: Raposa/ Serra do Sol foi identificada, demarcada e homologada a muito custo durante três décadas e sob procedimento inteiramente legal. (Manuela Carneiro da Cunha e Ana Valéria Araújo, FSP, 26/04/2008 [Tendências/Debates, p. A3], p. 34)

Les riziculteurs procèdent à de violentes attaques, répétées, contre les Indiens ( $O s$ arrozeiros atacaram os índios com violência)

Eram 6h da manhã de 23 de novembro de 2004, quando a comunidade Jauari foi despertada por tiros, gritos, roncos de máquinas. Quarenta homens armados mataram galinhas, porcos e cães, e deram dois tiros no macuxi 
Jocivaldo Constantino, um deles na cabeça. De lá marcharam para destruir as comunidades indígenas Brilho do Sol, Retiro São José e Homologação. Nas quatro aldeias derrubaram, com tratores, 37 casas e incendiaram os escombros, sem poupar a igreja, a escola e o posto de saúde; isolaram as áreas e fecharam as estradas. Ficaram desabrigadas 131 pessoas. (Frei Betto, $C B$, 09/05/2008 [Opinião, p. 25], p. 63)

C'est l'occupation du territoire par les riziculteurs qui est illégale ( $A$ ocupação do territorio indigena pelos arrozeiros è ilegal)

As terras indígenas são de propriedade da União e os índios têm o direito à ocupação permanente e ao usufruto exclusivo das riquezas nelas existentes (artigo 231 da Constituição). Se invadir propriedade da União é fato que deve ser tolerado, sem incomodar os invasores, não há por que condenar outras invasões de terras. Ainda mais, a atitude dos invasores, que são ricos integrantes do agronegócio, proclamando que resistiriam pela força à sua expulsão pela Polícia Federal, como noticiou o Estadão, configurou o crime de desobediência definido no Código Penal. Dalmo de Abreu Dallari, OESP, 25/04/2008 [Fórum dos Leitores, p. 32], p. 31)

Le Tribunal Suprême Fédéral (STF) suspend pourtant l'action d'expulsion des riziculteurs par la police fédérale ( $O$ Supremo Tribunal Federal impede a desintrusão dos arrozeiros pela Polícia federal)

Trata-se, é claro, de uma campanha bem orquestrada, conectando uma situação regional ao espaço público nacional e às principais instituições da República. Mas quais são os fatos? A Polícia Federal foi chamada a fazer a desintrusão de uma área indígena quando já encerrado o procedimento homologatório. Alguns poucos produtores de arroz se armaram, com o apoio político local, para resistir, queimando pontes e ameaçando usar táticas terroristas. Esses produtores não possuem títulos legítimos sobre as terras que ocupam. Contudo, acatando ação proposta pelo governo de Roraima, o Supremo Tribunal Federal (STF) suspendeu a operação da Polícia Federal, adiando-a até o julgamento do mérito da questão, em meio às críticas furiosas contra os direitos indígenas.

$[\ldots]$

É triste constatar que se faça tanto alarde em torno de 1,7 milhão de hectares habitados por 18 mil índios, com ocupação ininterrupta por milhares de anos, e poucos se escandalizem com a apropriação ilegal de áreas imensas, às vezes maiores do que essa, por um só proprietário.

Boa parte dos títulos de terra na Amazônia possui cadeias dominais duvidosas, gerando situações de superposição e de violência. Enquanto o Estado brasileiro não regularizar esta situação, o desenvolvimento econômico na região tende a ser um rótulo enganoso para a depredação ambiental, a 
reprodução da miséria e a usurpação do patrimônio público. (Boris Fausto e Carlos Fausto, OESP, 28/04/2008 [Espaço Aberto, p. A2], p. 44)

6-Quel enjeu dans cette polémique? Les conceptions relatives aux Indiens brésiliens (Que jogo nessa polémica? As concep̧̧̃es relativas aos indios brasileiros)

O que está em jogo nessa polêmica não é apenas a Raposa Serra do Sol. É um princípio constitucional que assegura a integridade física e cultural dos índios. Transformar as áreas indígenas em « ilhas » é uma velha idéia (e um velho sonho) conservadora. O saudoso ministro do STF Victor Nunes Leal, ao tratar de questão similar, já alertava para os perigos, asseverando: « Aqui não se trata do direito de propriedade comum. [...] Não está em jogo [...] um conceito de posse, nem de domínio, no sentido civilista dos vocábulos; trata-se do hábitat de um povo ». (Boris Fausto e Carlos Fausto, OESP, 28/04/2008 [Espaço Aberto, p. A2], p. 44)

Boa parte dessas dificuldades se deve ao fato de que Raposa Serra do Sol sintetiza, de maneira exemplar, as contradições da sociedade brasileira.

Falamos de uma área de 1,7 milhão de hectares - Portugal e Bélgica têm, juntos, aproximadamente esse tamanho -, em que vivem, na fronteira com a Guiana e a Venezuela, cinco etnias diferentes. Joaquim Nabuco, em sua célebre defesa na Questão da Guiana, referiu-se expressamente à presença dos macuxis para sustentar a posse brasileira sobre o território disputado com o país vizinho.

A maioria dos índios conserva língua, usos e costumes tradicionais. Ao longo do tempo, foiestimulada a formação de pequenas colônias e de enclaves, cujo crescimento previsivelmente tenderia a exacerbar os conflitos fundiários, colocando em risco a própria sobrevivência física e cultural das comunidades tradicionais, com a destruição de seu habitat natural.

Há, portanto, uma sobreposição de regimes jurídicos especiais, todos constitucionalmente protegidos - defesa da soberania territorial, direitos dos índios, conservação ambiental, autonomia do ente federativo e respeito a sua legítima aspiração ao desenvolvimento.

Para chegar a uma solução justa e equilibrada, foram feitas várias visitas « in loco » e executados rigorosos estudos técnicos. Todas as partes envolvidas foram consultadas e ouvidas.

[...]

É hora de sedimentar os progressos históricos alcançados ao longo de duas décadas, graças ao esforço daqueles que se envolveram na construção dessa bela obra jurídica e política.

Nossos filhos e netos saberão reconhecer sua fundamental importância para a idéia que temos de nação. (Márcio Thomaz Bastos e Luiz Armando Badin, FSP, 20/04/2008 [Tendências/Debates, p. A3], pp. 19-20) 
7 -L'adhésion du Brésil à la Déclaration onusienne des droits des peuples indigènes est un acte d'État et non d'un gouvernement ( $A$ adesão do Brasil à declaração da ONU dos Direitos dos Povos Indigenas è fato do Estado, não è fato d'um governo)

O Estado brasileiro - e não o governo - e seu marco regulatório, seguindo tendência global, reorientaram sua forma de se relacionar com os povos indigenas: de uma atuação tutelar e integracionista para uma postura de reconhecimento e respeito à sua autonomia e aos seus direitos originários às terras que tradicionalmente habitam - traduzida tanto na Constituição quanto na adesão do Brasil à Declaração dos Direitos dos Povos Indígenas da ONU, em setembro de 2007. (Henyo T. Barreto Filho, $C B, 26 / 04 / 2008$ [Opinião, p. 29], p. 36)

A recente "Declaração dos Direitos dos Povos Indígenas ", adotada pela Assembléia Geral da ONU, em setembro de 2007, neste sentido, ainda amplia a proteção dos índios, que «são iguais a todos os outros povos, ainda que reconhecendo o direito de todos os povos a serem diferentes, considerarem a si próprios diferentes e serem respeitados como tais ». (César Augusto Baldi, Revista Consultor Jurídico, 23/04/2008, p. 27)

8 - Quelques points de vue relatifs aux principaux « dangers » évoqués (Alguns pontos de vista sobre os perigos temidos)

Malédiction sur les ONG et ingérence internationale ! (Ingerência estrangeira e malditas $O N G$ !)

Esse perigo, sobre o qual temos alertado toda a sociedade brasileira há mais de dez anos, tem a ver com a Declaração Universal dos Direitos dos Povos Indígenas, aprovado pela Organização das Nações Unidas (ONU) em 13 de setembro de 2007. Essa declaração é quase o ato final de um persistente processo que, nos últimos 20 anos, tem sido levado a efeito por influentes e bem estruturadas organizações não-governamentais (ONGs).

Caso a Declaração venha a ser referendada pelo Congresso, ganhará força de emenda constitucional, conforme prevê a própria Constituição Lembro que a Lei Maior diz, no seu artigo $5^{\circ}$, que tratados internacionais referentes a direitos humanos referendados pelo Congresso passam a valer como emendas constitucionais. Em tese, nada impediria que algum destes vários líderes indígenas, muito bem instruídos e preparados, declarasse a independência de sua "nação ", apartada do Brasil. (General Luiz Gonzaga Lessa, OESP, 25/04/2008 [Nacional, p. A14], p. 30)

Une crainte délirante... (Espantalho...)

Vem então outro surrado espantalho: ONGs internacionais ou com ligações internacionais. Somos inteiramente favoráveis a que se separe o joio do trigo. Se há indícios, que se investiguem, mas uma teoria conspiratória 
generalizada lembra o protocolo dos sábios de Sião: serve apenas para justificar o arrepio da ordem legal. (Manuela Carneiro da Cunha, FSP, 26/04/2008 [Tendências/Debates, p. A3], p. 34)

Territoire, nation et souveraineté : pour une continuité nécessaire du territoire " de rio à rio » (Território, nação y soberania : em favor da continuidade territorial de rio a rio)

O pesquisador em etnoecologia do Instituto de Pesquisa da Amazônia (Inpa), Vincenzo Lauriola, ressalta que a demarcação contínua da Tirss representa um modelo importante de gestão sócio-ambiental e de desenvolvimento sustentável, por ser inteiramente delimitado por fronteiras naturais. " $\mathrm{Na}$ sua luta pela área única "de rio a rio", os índios demonstram sabedoria ambiental, buscando indiretamente evitar problemas que afetam outras áreas indígenas, como o Parque Indígena do Xingu, cujas condições ambientais são gravemente ameaçadas pelo desmatamento provocado pela expansão das monoculturas e da pecuária nas nascentes dos rios que o atravessam, devido ao fato que ficaram fora da área demarcada ».

A opção política crucial então era: demarcar a terra em ilhas, como queria a oligarquia local, oumanter a integridade do conjunto, evitando seu estilhaçamento. (Flávia Dourado, Com Ciência, 08/05/2008, p. 59)

La démarcation menace la continuité du territoire de l'Union ( $A$ demarcą̧ão ameaça a continuidade do territorio da União)

Hoje chegamos a um momento de decisão. A ONU aprovou a Declaração dos Direitos dos Povos Indígenas em setembro de 2007, que prevê, simplesmente, a autodeterminação para as TIs, além de outros direitos que as tornam enclaves dentro do território nacional. Considerando as dezenas de TIs nas faixas de fronteiras e no interior, o que vai ser uma 'terra dividida em ilhas' é o próprio País. A Declaração recebeu, lamentavelmente, o voto favorável do Brasil. Desnecessário dizer que EUA, Austrália e Canadá votaram contra. (Luiz Eduardo Rocha Paiva, OESP, 07/05/2008 [Espaço Aberto, p. A2], p. 57)

La démarcation menace la souveraineté de l'État: balkanisation de l'Amazonie (A demarcação ameaça a soberania do estado : balcanisação da Amazônia)

Há um grande perigo em gestação na fronteira Norte do País: a balcanização da Amazônia, ou seja, a transformação daquela vasta região em algo semelhante ao que ocorreu no Kosovo, nos Bálcãs, com conseqüente risco à soberania brasileira. Este tema tem muito a ver com a tentativa de transformar toda aquela área, onde vive boa parte das nações indígenas brasileiras, em uma nação distinta do Brasil. (General Luiz Gonzaga Lessa, OESP, 25/04/2008 [Nacional, p. A14], p. 30) 
Les étrangers sont complices ou conseillers des Indiens (Os estrangeiros são cúmplices ou conselheiros dos indios)

Isso tem muito a ver com a influência estrangeira sobre os índios, tema que está no fulcro do projeto apresentado pela Secretaria Nacional de Justiça. O pior é que este atentado não tem sido coibido pelo governo, que, obviamente, percebe o risco, mas tem se omitido e não de agora. (General Luiz Gonzaga Lessa, OESP, 25/04/2008 [Nacional, p. A14], p. 30)

C'est la pression internationale qui gère les démarcations de territoire (A pressão por parte dos organismos internacionais incentivam as demarcações)

Existem três eventos que, coincidência ou não, mostram sucessivos governos criando TIs ou unidades de conservação em faixas de fronteiras quando tinham algum interesse em negociação internacional. Em 1991, sob ameaça de boicote da conferência ecológica Rio-92, foi criada a TI Ianomâmi. Em 2002, quando houve a Conferência Rio+10 na África do Sul, foi criado o Parque Nacional do Tumucumaque, onde existe uma TI. Em 2005, quando o Brasil pleiteava um assento permanente no Conselho de Segurança da ONU, foi definida a TI Raposa Serra do Sol em terras contínuas, e não em « ilhas ». (Luiz Eduardo Rocha Paiva, OESP, 07/05/2008 [Espaço Aberto, p. A2], p. 57)

Les Indiens sont une menace pour l'unité du pays (Índios representam uma ameaça à unidade do pais)

A se confirmar essa tendência, teremos retalhado o Brasil em 227 nações, com 180 diferentes idiomas. O crime contra o Brasil e sua soberania e unidade territorial terá sido perpetrado. Onde está a sociedade civil que não se manifesta? (General Luiz Gonzaga Lessa, OESP, 25/04/2008 [Nacional, p. A14], p. 30)

9 - Les ethnologues voudraient un " parc anthropologique » (Os antropólogos queriam um jardim antropológico)

Por outro lado, a perpetuação de culturas nativas, em que se fundamenta, no Brasil, a política de reservas, carece de sentido. Em termos antropológicos, pois é impossível sustar o processo civilizatório. As populações civilizadas do mundo são descendentes de populações tribais, que seguiram, em todos os países, o secular caminho que leva paleolíticos a se transformarem em neolíticos e estes, em civilizados. Criar um "jardim antropológico", à semelhança de um jardim zoológico, é uma insensatez. Cabe ao governo federal zelar pela unidade do país, e não contribuir para autonomizar supostas nações indígenas que, no limite do caso, poderiam apelar para a ONU para lhes salvaguardar a independência e ser objeto de penetração estrangeira. (Helio Jaguaribe, FSP, 26/04/2008 [Tendências/Debates, p. A3], p. 32) 
10 - Accumulation des maux causés par la démarcation : quelques contrastes solides (Inventário das maldades causadas pela demarcação)

Frontière troublée versus frontière sûre (Fronteira conflituosa vs fronteira assegurada)

Na Raposa Terra do Sol a fronteira é viva e conflituosa. A Venezuela e nós disputamos com a Inglaterra, desde o século 19, a fronteira com a Guiana Britânica. Árbitro, o rei da Itália nos fez perder pequena região, chamada Depressão do Rio Pirara, e a Venezuela todo o extenso território a oeste do rio Essequibo, o que a Venezuela periodicamente tenta reconquistar. A segurança de nossa fronteira tem sido garantida simbolicamente, já que a tropa militar brasileira, para neutralizar qualquer eventual ameaça, como é seu dever constitucional, the é distante. (Jarbas Passarinho, CB, 06/05/2008 [Opinião, p. 19], p. 53)

Indiens acculturés versus Indiens primitifs (Índios aculturados vs índios primitivos)

Os índios lá vivem em íntima colaboração com não índios. Já estão aculturados. Dirigente atual da Funai diz que a palavra aculturação é démodé. Usada pela primeira vez em 1936 por Robert Redfield, continua adotada por antropólogos para significar o contato entre culturas diferentes e as transformações que ocorrem. Ora, tive testemunhos de que os índios macuxis já tinham até vereadores municipais, conviveram com pecuaristas por centenas de anos e, mais recentemente, com plantadores de arroz. Logo, não há contradição minha. Ianomâmis são primitivos. Os macuxis não. (Jarbas Passarinho, $C B, 06 / 05 / 2008$ [Opinião, p. 19], p. 53)

Les ONG et le Parti Travailliste (PT) malignement ligués contre l'autre Brésil (le vrai) (ONG e o PT ligados frente ao " outro » Brasil)

Mas o perigo real está na atuação perniciosa de certas ONGs, e potencial na lastimável resolução dos direitos indígenas, votada inclusive pelo Brasil petista. (Jarbas Passarinho, CB, 06/05/2008 [Opinião, p. 19], p. 53)

11 - Un peu d'histoire récente? Visions contrastées (Um toque de história recente? visões contrastivas)

A política indigenista no Brasil não foi, originariamente, formulada pelo governo federal, e sim por esse grande pioneiro que foi o general Rondon.

Encarregada da extensão das linhas telegráficas até Cuiabá, a Missão Rondon, como foi designada, se defrontou com as populações indígenas do interior do país. A política adotada por Rondon foi a de total respeito aos índios, reconhecidos como legítimos proprietários das terras.

Meu saudoso pai, general Francisco Jaguaribe de Mattos, então jovem capitão, foi o geógrafo e cartógrafo da missão. Dele tenho narrativas diretas 
de como se procedia então. Seus membros, nos freqüentes encontros com os índios, os abordavam pacificamente, incorporando os que desejassem. O lema de Rondon era: "Morrer se necessário, matar, nunca ». (Helio Jaguaribe, FSP, 26/04/2008 [Tendências/Debates, p. A3], pp. 32-33)

Commentaire : On se croit dans un discours de défense des Indiens? (Comentário : se trata de uma opinião em favor dos índios?)

A política indigenista de Rondon partia do suposto de que o índio era o brasileiro nativo, que devia ser tratado respeitosamente pelos civilizados e induzido, pacificamente, a se incorporar à cidadania, recebendo conveniente educação e assistência. (Helio Jaguaribe, FSP, 26/04/2008 [Tendências/ Debates, p. A3], pp. 32-33)

Mais la roue du discours tourne : l'incorporation des Indiens doit aboutir à l'assimilation (Outro som : incorporação dos índios deve chegar à assimilação)

A República manteve a política indigenista de Rondon. De acordo com suas idéias (ele mesmo tendo ascendência indígena), estimava-se que, gradualmente, a total população indígena, ora da ordem de 700 mil entre 190 milhões de habitantes, seria incorporada à cidadania brasileira. (Helio Jaguaribe, FSP, 26/04/2008 [Tendências/Debates, p. A3], pp. 32-33)

Introduction des ethnologues... (Introdução dos etnólogos...)

Em anos mais recentes, a política indigenista brasileira passou a ser orientada por etnólogos. Estes, diversamente de Rondon, não intentavam a pacífica incorporação do índio, mas a preservação das culturas indígenas. Para isso, adotou-se a prática da delimitação de amplas áreas nos sítios povoados por indios, como reservas.

A política de reservas vem sendo aplicada sem levar em conta os imperativos de defesa nacional, o que ocorre nos diversos casos em que elas se estendem até nossas fronteiras com países vizinhos. As autoridades militares têm alertado o governo, com toda a razão, sobre o perigo da prática.

Por essas e outras razões, a política indigenista brasileira requer uma urgente a ampla revisão.

Desde logo, independentemente da nova orientação que se lhe dê, é preciso estabelecer uma faixa que acompanhe as fronteiras do Brasil com outros países e dela excluir as reservas indígenas. Em termos mais amplos, importa questionar: que objetivos deve ter tal política, ademais da proteção do índio? (Helio Jaguaribe, FSP, 26/04/2008 [Tendências/Debates, p. A3], pp. 32-33)

Conclusions divergentes (Conclusões divergentes)

Entre discipline - obéir à la loi - et loyauté - désobéir à la loi (Entre disciplina - obedecer à lei-e lealdade - desobedecer à lei)

Eis, portanto, estabelecido o dilema entre disciplina e lealdade. Trata-se de um aparente dilema, pois a lealdade à Pátria, à Nação e ao Estado é, em síntese, 
manifestação de disciplina em seu grau mais elevado, considerando a missão constitucional das Forças Armadas e o juramento do militar à Bandeira Nacional. (Luiz Eduardo Rocha Paiva, OESP, 07/05/2008 [Espaço Aberto, p. 12], p. 57)

" Il ne faut pas revenir en arrière » (" Não podemos volver atraz »)

A presença soberana e incontrastável do Estado brasileiro foi conciliada com a proteção do meio ambiente e da diversidade étnica e cultural, bens valiosos que a Constituição, generosamente, soube reconhecer. Falta apenas finalizar a execução do decreto presidencial, concluindo o processo de extrusão da minoria remanescente. Ela já teve mais de três anos para deixar a área invadida. Não é momento de retroceder. (Márcio Thomaz Bastos e Luiz Armando Badin, FSP, 20/04/2008 [Tendências/Debates, p. A3], pp. 19-20)

\section{DOCUMENT 4}

\section{Nota de apoio}

Organizações da sociedade civil querem respeito aos direitos indígenas e presença da democracia em Roraima, Instituições de destaque como a CNBB, SBPC, ABONG, FDDI, Instituto Ethos e ABA entre outras,

Divulgam nota de apoio à retirada dos invasores da Terra Indígena RaposaSerra do Sol e exigem que se respeite o Estado Democrático de Direito em Roraima.

O abaixo-assinado está aberto à adesão de instituições e pessoas.

Em vista do debate que vem ocorrendo no STF e pela mídia acerca da demarcação e da desintrusão da Terra Indígena Raposa-Serra do Sol, em Roraima, os abaixo-assinados têm a declarar o seguinte:

1. Desde a colônia, reconhecem-se os direitos dos índios sobre suas terras, direitos que figuram também em todas as Constituições Brasileiras desde 1934. Desde a colônia também, os interesses econômicos e a cobiça de territórios encontraram subterfúgios para eludir a aplicação dessas leis. É por causa dessa cobiça que as populações indígenas no Brasil mais numerosas se encontram para além da antiga fronteira econômica, tendo sido dizimadas nas regiões de antiga colonização. A Constituição de 1988 explicitou os direitos dos índios sobre suas terras e afirmou o caráter originário desses direitos. É inconcebível que neste novo milênio, se recorra outra vez a casuísmos para expulsar os índios das áreas que passaram a ser cobiçadas, repetindo assim práticas que deveriam nos envergonhar.

2. A ocupação tradicional indígena sobre a extensão integral da Terra Indígena Raposa Serra do Sol é comprovada por copiosa documentação 
histórica e foi determinante para a definição da fronteira brasileira com a Guiana. Mais de 18 mil índios Macuxi, Wapixana, Ingarikó, Taurepang e Patamona vivem nessa área, organizados em mais de uma centena de comunidades, que praticam suas línguas e costumes.

3. O processo de demarcação dessa terra se desenvolve desde o fim dos anos 1970. Foi identificada pela Funai em 1993, com a extensão atual, depois foi demarcada administrativa e fisicamente durante o governo Fernando Henrique Cardoso (1998) e finalmente homologada pelo governo Lula em 2005, tendo sido rejeitadas todas as contestações apresentadas.

4. A quase totalidade de não-índios que chegaram a ocupá-la de boa fé foi indenizada ou reassentada e a resistência à desintrusão da área se reduz a um pequeno grupo de arrozeiros, que se instalou ao sul da Terra Indígena no início dos anos 1990 e ampliou sua área de produção, mesmo sabendo tratar-se de terras de propriedade da União.

5. Não existe nenhuma cidade instalada na Terra Indígena Raposa Serra do Sol, mas apenas uma vila, com a quase totalidade da população atual sendo indígena. A Vila Surumu foi criada por fazendeiros que já saíram da Terra Indígena e falta apenas a Funai indenizar 11 moradores não-índios. A vila de Uiramutã, sede do município de mesmo nome, criado em 1995, foi excluída da Terra Indígena em 2005. A maior parte dos habitantes da sede deste município são moradores da aldeia indígena Uiramutã. Havia três bases de garimpo chamadas Socó, Mutum e Água Fria, as quais, com a retirada dos garimpeiros em 1994, passaram a ser reocupadas por indígenas. A Funai indenizou e retirou todos os não-índios e hoje essas localidades estão totalmente integradas às aldeias.

6. As terras indígenas são bens de propriedade da União, indisponíveis e inalienáveis, e hoje prestam relevantes serviços ambientais ao País, ao proteger as florestas contra o avanço do desmatamento, que destrói as fontes de água, altera o regime de chuvas e elimina a biodiversidade.

7. A Constituição preconiza a harmonia entre o pleno reconhecimento dos direitos indígenas e a presença do Estado nas Terras Indígenas, inclusive para a promoção da defesa nacional em áreas situadas em faixa de fronteira, que diz respeito à indispensável proteção do território e da própria população indígena. Hoje há bases militares em várias terras indígenas, inclusive em Raposa Serra do Sol, e parte significativa dos soldados é indígena.

8. Raposa Serra do Sol não é a única e nem a maior Terra Indígena situada em faixa de fronteira; a demarcação dessas terras contribuiu para a regularização fundiária, reduziu conflitos e não criou qualquer dificuldade para a atuação do Estado, e das Forças Armadas em particular, mesmo em regiões mais críticas, como a fronteira com a Colômbia. 
9. Nunca surgiu em nenhuma Terra Indígena qualquer movimento que atentasse contra a integridade do território nacional, nem qualquer ação insurgente contra o Estado brasileiro.

10. A área de Raposa Serra do Sol representa 7,7 \% do território de Roraima, sendo que uma parte com dupla destinação (área de conservação e terra indígena). O status de Terra Indígena reconhecido em $46,13 \%$ do território de Roraima tem razões históricas decorrentes da ocupação imemorial e não é discrepante da representação efetiva da população indígena no âmbito da população rural do estado.

11. O processo de demarcação de uma Terra Indígena não cria nada, apenas reconhece e protege uma situação de fato, qual seja, a ocupação tradicional indígena de um território. Todos os povos indígenas que habitam os locais onde hoje se encontram as fronteiras brasileiras já estavam ali muito tempo antes delas serem politicamente estabelecidas.

12. A existência de terras federais com destinações específicas (Terras Indígenas e Unidades de Conservação federais) em Roraima não impede a sua governabilidade e o exercício de direitos pelos demais segmentos da sociedade local sobre o seu território. Excluídas essas terras federais, Roraima ainda conserva extensão superior à do Estado de Pernambuco, onde vive uma população dez vezes maior. Por tudo isto, os signatários esperam que o STF não tarde a se pronunciar sobre o caso, encerrando essa polêmica que prolonga conflitos desnecessários, reafirmando a plenitude dos direitos constitucionais indígenas e a sua harmonia com os interesses nacionais.

\section{Abréviations}

$\begin{array}{ll}\text { ABA } & \text { Associação Brasileira de Antropología } \\ \text { CB } & \text { Correio Braziliense } \\ \text { DDPI } & \text { Declaração dos Direitos dos Povos Indigenas } \\ \text { FSP } & \text { Folha de São Paulo } \\ \text { FUNAI } & \text { Fundação Nacional do Índio } \\ \text { INCRA } & \text { Instituto Nacional de Colonização e Reforma Agrária } \\ \text { INPA } & \text { Instituto de Pesquisa da Amazônia } \\ \text { ISA } & \text { Instituto SocioAmbiental } \\ \text { MNDH } & \text { Movimento Nacional de Direitos Humanos } \\ \text { OESP } & \text { O Estado de São Paulo } \\ \text { PT } & \text { Partido trabalhista } \\ \text { STF } & \text { Supremo Tribunal Federal } \\ \text { TI } & \text { Terra Indigena } \\ \text { TIs } & \text { Terras Indigenas } \\ \text { TIRSS } & \text { Terra Indigena Raposa Serra do Sol }\end{array}$




\section{Notes}

1. Ce dossier a été préparé par Aurore Monod Becquelin sur documents.

2. Littéralement " grillonneurs ", ceux qui falsifient des documents en les mettant dans une boîte à grillons pour les jaunir et les ronger.

3. L'Institut Socioambiental (ISA) est une association à but non lucratif, qualifiée d'Organisation de la Société Civile d'Intérêt Public (OSCIP), fondée le 22 avril 1994 par des personnalités de formation et d'expérience reconnues dans la lutte pour les droits sociaux et environnementaux. Son objectif est de défendre les biens et les droits sociaux, collectifs et « diffus » [terre dont la propriété et l'usage sont indivis], relatifs au milieu écologique, au patrimoine culturel, aux droits des hommes et des peuples. L'ISA fournit études et recherches, implante des projets et des programmes qui promeuvent la conservation socioécologique, valorisant la diversité culturelle et biologique du pays. 